
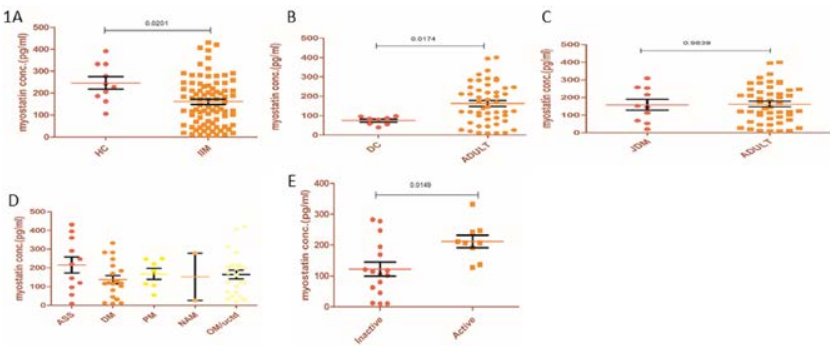

Figure 1. Serum Myostatin levels in IIM as compared with healthy controls (A) and disease controls (B). Levels in juvenile myositis as compared with adult IIM (C) and in various subsets of IIM (D). Serum Myostatin levels in active and inactive disease (E).

Although Follistatin was lower in IIM than HC (198.4 vs 243.6, $p=<0.0001$ ), the neither Follistatin nor Myostatin: Follistatin ratios differ between subsets, and in active versus inactive disease Figure $2 \mathrm{~A}-\mathrm{D}$ ). On follow-up, the serial Myostatin estimation paralleled change in disease activity.

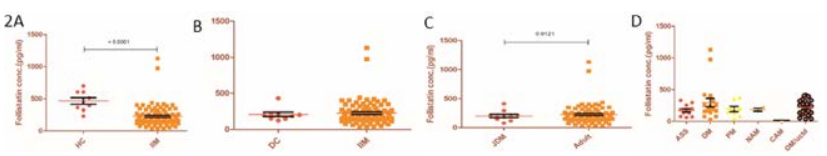

Figure 2. Serum Follistatin levels in IIM as compared with healthy controls (A) and disease controls (C). Levels in juvenile and adult IIM (D) and in various subsets of IIM (D).

Conclusion: Elevated serum Myostatin levels in active myositis raise the possibility of accelerated senescence in the inflamed muscle tissues which need further investigation.

Acknowledgments: : Partly funded by APLAR and IRA research grants awarded to LG.

Disclosure of Interests: None declared

DOI: 10.1136/annrheumdis-2020-eular.5641

\section{SAT0291 \\ THE ROLE OF X-LINKED INHIBITOR OF APOPTOSIS PROTEIN (XIAP) IN SYSTEMIC SCLEROSIS}

C. Bergmann ${ }^{1}$, L. Hallenberger ${ }^{1}$, B. Merlevede ${ }^{1}$, C. Dees ${ }^{1}$, C. W. Chen ${ }^{1}$, O. Distler ${ }^{2}$, G. Schett ${ }^{1}$, J. Distler'. ${ }^{1}$ Department Internal Medicine IIIRheumatology, Erlangen, Germany; ${ }^{2}$ University Hospital of Zürich, Zürich, Switzerland

Background: Pathologic activation of fibroblasts is a central feature of fibrotic tissue disease in Systemic Sclerosis (SSc). Although individual key signaling pathways of fibroblast activation such as transforming growth factor $\beta$ (TGF $\beta$ ) and $\mathrm{WNT} / \beta$-catenin signaling have been identified, the consequences of the concomitant upregulation of these pathways and their crosstalk are incompletely characterized. Given the high medical need, the identification of mutual activation and amplification loops of profibrotic signals is essential to identify novel candidates for antifibrotic therapies. XIAP (X-linked inhibitor of apoptosis protein) is a ubiquitously expressed member of the IAP protein family which are implicated in the regulation of various cellular functions and tissue turnover. XIAP was recently described to be implicated in WNT/ $\beta$-catenin signaling and TGF $\beta$ signaling. Objectives: The aim of this study is to characterize the role of XIAP in fibrotic disease.

Methods: XIAP-expression was analyzed by GPCR, IF and Western blot. XIAP was targeted pharmacologically and with siRNA. The activation of WNT/ $\beta$-catenin signaling was assessed by analyses of WNT target genes, by TOPflash/FOPflash luciferase reporter assay and in reporter mice. In vivo, XIAP inhibition was analysed in two different models of fibrosis.

Results: The expression of XIAP is increased in the skin of SSc patients compared to matched healthy individuals with a particular prominent expression in fibroblasts. The overexpression of XIAP is more pronounced in SSc patients with diffuse and active skin fibrosis compared to SSc patients with limited and inactive disease. The overexpression of XIAP is also reflected in several experimental fibrosis models: the model of sclerodermatous graft versus host disease, the model of bleomycin induced skin fibrosis and Topoisomerase I induced fibrosis (Topol) mice. TGF $\beta$ induces the expression of XIAP in vitro and in vivo and treatment with the TGF $\beta 1$ receptor antagonist SD208 reverses the TGF $\beta$ induced expression of XIAP. Inhibition of XIAP with embelin or siRNA reduces the TGF $\beta$ induced activation of fibroblasts with reduced collagen release and reduced expression of myofibroblast markers. In addition, XIAP inhibition reverted the activated fibroblast phenotype in SSc fibroblasts with reduced expression of stress fibers and
aSMA. The antifibrotic effects of XIAP inhibition occurred in non-toxic doses as demonstrated by MTT and by TUNEL staining. In vivo, inhibition of XIAP reduced skin fibrosis in the models of bleomycin induced skin fibrosis and in Topol-induced skin and lung fibrosis as demonstrated by analysis of dermal thickening, dermal hydroxyproline content and by analysis of myofibroblast differentiation. Mechanistically, XIAP inhibition reduced the activation of WNT/ $\beta$-catenin signaling as demonstrated by TOPflash reporter assays and by the analysis of WNT target genes.

Conclusion: XIAP is upregulated in SSc fibroblasts and murine SSc models in a TGF $\beta$-dependent manner and promotes fibroblast activation by fostering canonical WNT signaling. Our data suggest that XIAP mediates an amplification loop between TGF $\beta$ and WNT/ $\beta$-catenin signaling. Inhibition of XIAP may thus be a novel approach to target aberrant WNT/ $\beta$-catenin signaling in fibrotic diseases.

Disclosure of Interests: Christina Bergmann: None declared, Ludwig Hallenberger: None declared, Benita Merlevede: None declared, Clara Dees: None declared, Chih-Wei Chen: None declared, Oliver Distler Grant/research support from: Grants/Research support from Actelion, Bayer, Boehringer Ingelheim, Competitive Drug Development International Ltd. and Mitsubishi Tanabe; he also holds the issued Patent on mir-29 for the treatment of systemic sclerosis (US8247389, EP2331143)., Consultant of: Consultancy fees from Actelion, Acceleron Pharma, AnaMar, Bayer, Baecon Discovery, Blade Therapeutics, Boehringer, CSL Behring, Catenion, ChemomAb, Curzion Pharmaceuticals, Ergonex, Galapagos NV, GSK, Glenmark Pharmaceuticals, Inventiva, Italfarmaco, iQvia, medac, Medscape, Mitsubishi Tanabe Pharma, MSD, Roche, Sanofi and UCB, Speakers bureau: Speaker fees from Actelion, Bayer, Boehringer Ingelheim, Medscape, Pfizer and Roche, Georg Schett Speakers bureau: AbbVie, BMS, Celgene, Janssen, Eli Lilly, Novartis, Roche and UCB, Jörg Distler Grant/research support from: Boehringer Ingelheim, Consultant of: Boehringer Ingelheim, Paid instructor for: Boehringer Ingelheim, Speakers bureau: Boehringer Ingelheim DOI: 10.1136/annrheumdis-2020-eular.3265

\section{SAT0292 INTEGRATIVE TRANSCRIPTOMIC AND FUNCTIONAL ANALYSIS REVEALS A ROLE OF DIMETHYL-A-KETOGLUTARATE IN TGFB-DRIVEN CYTOSKELETON REGULATION AND MYOFIBROBLAST DIFFERENTIATION}

B. Burja ${ }^{1,2}$, G. Kania ${ }^{2}$, M. Tomsic ${ }^{1}$, S. Sodin-Šemrl ${ }^{1}$, O. Distler ${ }^{2}$, K. Lakota ${ }^{1}$ M. Frank-Bertoncelj ${ }^{2}{ }^{1}$ University Medical Centre Ljubljana, Department of Rheumatology, Ljubljana, Slovenia; ${ }^{2}$ Center of Experimental Rheumatology, University Hospital Zurich, Zurich, Switzerland

Background: Myofibroblasts are the orchestrators of aberrant extracellular matrix (ECM) remodelling in fibrosis. Actin cytoskeleton is a central hub that integrates mechanical signals to promote myofibroblast differentiation and ECM remodelling. Targeting these pathways could represent a novel antifibrotic strategy. We have recently shown that metabolic intermediate dimethyl-a-ketoglutarate (dm-aKG) blocks TGF $\beta$-driven myofibroblast differentiation in dermal fibroblasts (DF).

Objectives: To investigate the mechanisms by which dm-aKG regulates TGF $\beta$ driven myofibroblast differentiation and inflammatory responses in DF.

Methods: DF from healthy controls and patients with systemic sclerosis (SSc) were treated with TGF $\beta(10 \mathrm{ng} / \mathrm{ml})$ and $/ \mathrm{or} \mathrm{dm}$ - $\mathrm{aKG}(6 \mathrm{mM})$ for $24 \mathrm{~h}$, $48 \mathrm{~h}$ and $72 \mathrm{~h}$ RNA sequencing (llumina 2000, $n=3$ per experimental group) was followed by the analysis of differentially expressed genes (DeSEQ2, log2 fold $\geq|0.5|, \mathrm{p}_{\text {adj }}<$ 0.01 ), pathway enrichment analysis (GO terms) and supervised PCA analysis (ClustVis). Protein amounts (fibronectin, aSMA, IL-6), cell contraction and apoptosis were measured with Western blot $(n=6)$, ELISA $(n=4)$, collagen gel contraction assay $(n=4)$ and real time Annexin $V$ assay $(n=6)$. Significance $(p<0.05)$ was determined by one-sample t-test or ANOVA with Tukey's correction for multiple comparisons.

Results: TGF $\beta$ (24h) altered the expression of 4076 genes in DF as determined by RNA-seq, among which 1864 genes were upregulated. The upregulated genes were enriched in GO biological processes/molecular functions/cellular compartments related to ECM organization ( $p=1 \mathrm{e}-07$ ), Wnt signalling $(p=5 e-06)$, actin binding $(p=3 e-07)$, focal adhesion $(p=1 e-$ $10)$, stress fibers $(p=3 e-07)$ and actin cytoskeleton $(p=3 e-06)$. Dm-aKG altered the expression of 589 genes in TGF $\beta$-treated DF compared to TGF $\beta$ only. The most downregulated pathways in DF treated with dm-aKG + TGF $\beta$ compared to TGF $\beta$ only included actin binding ( $p=5 e-05)$, muscle contraction $(p=0.001)$, ECM organization $(p=0.008)$, focal adhesion $(p=0.01), Z$ disk $(p=0.01)$ and stress fibers $(p=0.03)$. Specifically, $d m$-aKG significantly $(p<0.01, \log 2>-0.5)$ decreased the expression of many TGF $\beta$-induced genes involved in actin organization and focal adhesion (NEXN, FRMD5, ANTXR1, ACTC1, LIMCH1, SORBS2, TGM2, CSRP2, CAP2, LMO7, FZD2), muscle contraction (SNTB1, LMOD1, ANKRD1, SULF1, JPH2, CAVIN4, OXTR, DYSF, FBXO32) and ECM organization (COL10A1, COL11A1, HAPLN1, MMP14, 
MMP3, SPINT2, GREM1, MATN3, ADAMTS4). The PCA analysis revealed that the experimental treatment (PC1, Fig $1 \mathrm{~A}$ ) accounted for $61 \%$ variability in the expression of these genes, while $19 \%$ was attributed to interdonor variability (PC2). Dm-aKG diminished TGF $\beta$-induced production of aSMA protein (72h, $p=0.02$, mean O.D. \pm SD in TGF $\beta+d m$ - $\alpha$ KG vs. TGF $\beta: 0.34$ \pm 0.38 vs. $3.1 \pm 2.3$ ) and repressed TGF $\beta$-driven secretion of fibronectin protein (72h, $p=0.047,0.5 \pm 0.1$ vs. $1.2 \pm 0.6)$. Dm- $a K G$ reduced the contractile capacity of TGF $\beta$-stimulated DF in collagen gel contraction assay $(p=0.003,0$ vs. $67.1 \pm 5.4 \%)$. Additionally, dm-aKG decreased TGF $\beta$-driven production of IL- 6 transcripts $(24 \mathrm{~h}, \mathrm{p}=0.05,2.9 \pm 0.6$ vs $1.9 \pm 0.3)$ and protein (24h, p=0.0005, $5.9 \pm 1.2$ vs $3 \pm 0.7$, Fig $1 B)$, but did not increase the apoptosis of DF (24h, $48 \mathrm{~h}, 72 \mathrm{~h})$
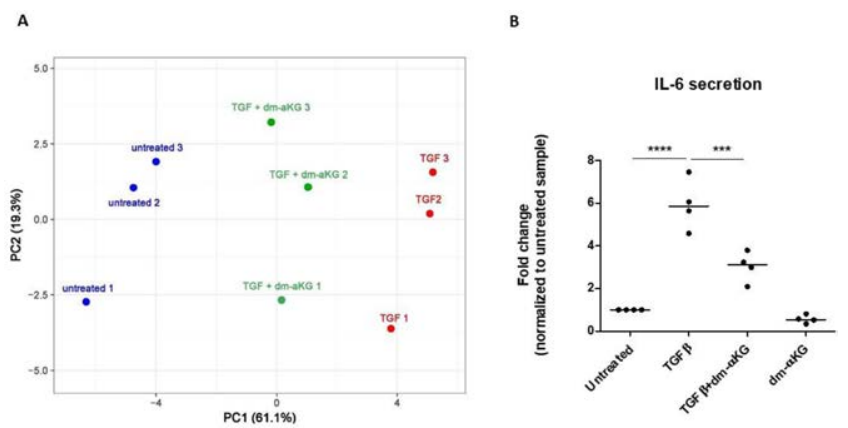

Fig 1. A Supervised PCA analysis of RNA-seq data. B. IL-6 secretion (ELISA).

Conclusion: Dm-aKG counteracted TGF $\beta$-induced myofibroblast differentiation by regulating the cytoskeleton organization and ECM dynamics in DF and blocked the TGF $\beta$-induced IL-6 production. This closely links metabolism to inflammatory and pro-fibrotic responses in DF. Therefore, regulating intracellular aKG might offer a novel strategy in combating the inflammatory and fibrotic stages of skin fibrosis in SSc.

Acknowledgments: This work was supported by a research grant from FOREUM Foundation for Research in Rheumatology.

Disclosure of Interests: Blaž Burja: None declared, Gabriela Kania: None declared, Matija Tomsic: None declared, Snežna Sodin-Šemrl: None declared, Oliver Distler Grant/research support from: Grants/Research support from Actelion, Bayer, Boehringer Ingelheim, Competitive Drug Development International Ltd. and Mitsubishi Tanabe; he also holds the issued Patent on mir-29 for the treatment of systemic sclerosis (US8247389, EP2331143)., Consultant of: Consultancy fees from Actelion, Acceleron Pharma, AnaMar, Bayer, Baecon Discovery, Blade Therapeutics, Boehringer, CSL Behring, Catenion, ChemomAb, Curzion Pharmaceuticals, Ergonex, Galapagos NV, GSK, Glenmark Pharmaceuticals, Inventiva, Italfarmaco, iQvia, medac, Medscape, Mitsubishi Tanabe Pharma, MSD, Roche, Sanofi and UCB, Speakers bureau: Speaker fees from Actelion, Bayer, Boehringer Ingelheim, Medscape, Pfizer and Roche, Katja Lakota: None declared, Mojca Frank-Bertoncelj: None declared

DOI: 10.1136/annrheumdis-2020-eular.3677

\section{SAT0293 EXOSOMES DERIVED FROM PLASMA OF SYSTEMIC SCLEROSIS (SSC) PATIENTS AND FROM SSC CULTURED FIBROBLASTS CONTAIN PRO-FIBROTIC MIRNA SIGNATURES AND COULD INDUCE MYOFIBROBLAST DIFFERENTIATION IN VITRO}

C. Corallo ${ }^{1}$, M. Cutolo ${ }^{2}$, S. Soldano ${ }^{2}$, E. Selvi ${ }^{1}$, F. Bellisai ${ }^{1}$, N. Giordano ${ }^{1}$. ${ }^{1}$ University of Siena, Scleroderma Unit, Department of Medicine, Surgery and Neurosciences, Siena, Italy; ${ }^{2}$ IRCCS San Martino Polyclinic Hospital, University of Genoa, Rheumatology, Genoa, Italy

Background: Exosomes generated great resonance in the last few years due to their important roles in different biological pathways and diseases, including systemic sclerosis (SSc) (1). They are lipid-like nanovesicles containing biomarkers, such as proteins, lipids, macromolecules and nucleic acids, including microRNA (miRNA) (2). Exosomes are implicated in intercellular communication by fusing and releasing their cargo into the target cells (3).

Objectives: In the present study, we evaluated the potential of exosomes deriving from plasma of SSc patients or generating from cultured SSc fibroblasts to drive the fibrotic signaling in the disease.

Methods: Exosomes were isolated from plasma of $n=10$ SSc patients and from $n=10$ control subjects. Exosomes were also purified from cell culture supernatants of SSc fibroblasts and of control fibroblasts. Exosome size and concentration were assessed by Nanosight Particle Tracking Analysis (NTA) and by transmission electron microscopy (TEM). The content of anti-fibrotic (let-7a, 146a, 200a, 223a) and pro-fibrotic $(150,155)$ miRNAs was assessed in all the plasma-derived and cell culture-derived exosome populations by semiquantitative real time PCR. Finally, isolated exosomes were used to stimulate control dermal fibroblasts in culture. Gene expressions (COL1A1, ACTA2 and TAGLN) were assessed by quantitative real time PCR (qRT-PCR) and protein levels (type-I-collagen, $\alpha$-SMA and SM22) by immunofluorescence (IF).

Results: Exosomes isolated from SSc plasma samples showed higher concentration $\left(3.3 \times 10^{10} \pm 1.1 \times 10^{10}\right.$ particles $\left./ \mathrm{mL}\right)$ compared to those isolated from control plasma ones $\left(1.5 \times 10^{10} \pm 0.4 \times 10^{10}\right.$ particles $\left./ \mathrm{mL}\right)(\mathrm{p}<0.01)$. The exosome size did not differ between SSc and control plasma samples and ranged from $50 \mathrm{~nm}$ to $150 \mathrm{~nm}$. Similar results were obtained with exosomes gener ated from fibroblast cultures: the concentration was higher in SSc fibroblasts $\left(1.1 \times 10^{10} \pm 0.2 \times 10^{10}\right.$ particles $\left./ \mathrm{mL}\right)$ than in control ones $\left(0.4 \times 10^{10} \pm 0.1 \times 10^{10}\right.$ particles $/ \mathrm{mL})(p<0.05)$ with no significant differences in size distribution. The content of all anti-fibrotic (let-7a, 146a, 200a, 223a) miRNAs was decreased in exosomes coming from both SSc plasma samples and from SSc fibroblasts with respect to control plasma samples $(p<0.05)$ and to control fibroblasts $(p<0.05)$. On the contrary, the pro-fibrotic $(150,155)$ miRNAs were significantly upregulated in exosomes deriving from SSc plasma samples and from SSc fibroblasts, with respect to control plasma samples $(p<0.05)$ and to control fibroblasts $(p<0.05)$. Finally, only exosomes coming from SSc plasma samples or SSc fibroblast cultures were able to induce pro-fibrotic gene (COL1A1, ACTA2 and TAGLN) and protein (type-l-collagen, a-SMA and SM22) expression in control fibroblasts. No pro-fibrotic induction was seen in presence of exosomes isolated from control plasma samples or control fibroblast cultures.

Conclusion: This study demonstrates that plasma from SSc patients contains higher concentration of exosomes compared to plasma from control subjects and SSc-derived exosomes contain specific pro-fibrotic miRNA signatures that can induce myofibroblast differentiation in vitro. These results suggest that exosomes could be fibrotic drivers towards non-affected areas in vivo, and they might represent novel targets for precision medicine treatments in SSc.

References:

[1] Zhu T, Wang Y, Jin H, Li L. The role of exosome in autoimmune connective tissue disease. Ann Med. 2019 Mar;51(2):101-108.

[2] Wermuth PJ, Piera-Velazquez S, Rosenbloom J, et al. Existing and novel biomarkers for precision medicine in systemic sclerosis. Nat Rev Rheumatol. $2018 \mathrm{Jul} ; 14(7): 421-432$

[3] Colletti M, Galardi A, De Santis M, et al. Exosomes in Systemic Sclerosis: Messengers Between Immune, Vascular and Fibrotic Components? Int J Mol Sci. 2019 Sep 4;20(18). pii: E4337.

Disclosure of Interests: Claudio Corallo: None declared, Maurizio Cutolo Grant/ research support from: Bristol-Myers Squibb, Actelion, Celgene, Consultant of: Bristol-Myers Squibb, Speakers bureau: Sigma-Alpha, Stefano Soldano: None declared, Enrico Selvi: None declared, Francesca Bellisai: None declared, Nicola Giordano: None declared

DOI: 10.1136/annrheumdis-2020-eular.4848

SAT0294

\section{IL33 ACTIVATES FIBROBLASTS AND INDUCES SKIN} FIBROSIS IN SYSTEMIC SCLEROSIS

X. Wu ${ }^{1}$, B. Ming ${ }^{1}$, L. Dong ${ }^{1} .{ }^{1}$ Tongji Hospital, Tongji Medical College, Huazhong University of Science and Technology, Department of Rheumatology and Immunology, Wuhan, China

Background: Systemic sclerosis (SSc) is a chronic immune-mediated autoimmune disease that is characterized by fibrotic changes of the skin and internal organs, which in turn leads to distortion of tissue structure and gradual loss of organ function. So far, there is still no treatment allows full recovery from this severe disorder. Therefore, it is of great social significance to study the pathogenesis of this disease and find new targets for treatment. Interleukin 33 (IL-33), which is a potent inducer of type 2 immune response, has been confirmed to be involved in the development and progression of multiple fibrotic diseases. However, the role and mechanism of IL-33 in SSc-related fibrosis remains unclear.

Objectives: To clarify the role of interleukin 33 (IL-33) and its receptor Suppression of tumorigenicity 2 (ST2) in the skin fibrosis of SSc, so to provides a new target for the treatment of fibrosis in patients with SSc.

Methods: The levels of IL-33 and ST2 was analysed in human samples, murine models of SSc and in cultured fibroblasts by immunohistochemistry and immu nofluorescence. The functional role of IL-33 was evaluated by detecting changes 